\title{
Association between maternal pre-delivery body mass index and offspring overweight/obesity at 1 and 2 years of age among residents of a suburb in Taiwan
}

\author{
Hsien-Kuan Liu ${ }^{1}$ ， Chien-Yi Wu ${ }^{1}$ ，Yung-Ning Yang ${ }^{1}$ ， Pei-Ling Wu ${ }^{1}$ ， Zong-Rong He ${ }^{1}$, San-Nan Yang ${ }^{1}$, Shu- \\ Leei Tey ${ }^{\text {Corresp. } 1}$ \\ 1 Department of Pediatrics, E-Da Hospital, I-Shou University, Kaohsiung, Taiwan \\ Corresponding Author: Shu-Leei Tey \\ Email address: ed104496@edah.org.tw
}

Background. Overweight and obesity among children can cause metabolic syndrome in adulthood and are a significant public health issue. Some studies suggest that maternal pre-pregnancy body mass index (BMI) and excessive gestational weight gain during pregnancy are associated with overweight and obesity in offspring. However, it is difficult to collect information on accurate pre-pregnancy BMI and pregnancy weight gain for women living in areas where medical resources are scarce. Maternal predelivery BMI might be predictive of the risk of overweight and obesity among offspring of pregnant mothers living in suburban areas.

Methods. We retrospectively collected data on term neonates with appropriate weights for their gestational age born between April 2013 and October 2015. We excluded neonates with major congenital anomalies or diseases and incomplete data. Mothers with systemic diseases or drug abuse were also excluded. Offspring body weights and heights at 1- and 2-years-old were recorded. Maternal pre-delivery BMI was divided into following groups: $<25 \mathrm{~kg} / \mathrm{m}^{2}, 25-29.9 \mathrm{~kg} / \mathrm{m}^{2}$, and $\geqq 30 \mathrm{~kg} / \mathrm{m}^{2}$.

Results. We included 261 mother-child pairs in this study. The BMIs of the offspring differed significantly among the 3 maternal pre-delivery BMI groups at the age of 2 years $\left(15.18 \pm 1.04 \mathrm{~kg} / \mathrm{m}^{2}, 15.83 \pm 1.28\right.$ $\mathrm{kg} / \mathrm{m}^{2}$, and $16.29 \pm 1.61 \mathrm{~kg} / \mathrm{m}^{2}, p<0.001$, respectively). After adjusting for potential cofounders possibly affecting weight using multivariate linear regression, the children's BMIs (adjusted 95\% $\mathrm{Cl}: 0.71(0.31$ to 1.11 ); $p=0.001$ ) and $\mathrm{BMI}$ percentiles (adjusted $95 \% \mathrm{Cl}: 15.80(7.32$ to 24.28 ); $p<0.001$ ) at the age of 2 years were significantly higher in those born to mothers with pre-delivery BMls of $25-29.9 \mathrm{~kg} / \mathrm{m}^{2}$ compared to mothers with pre-delivery BMls $<25 \mathrm{~kg} / \mathrm{m}^{2}$. Maternal pre-delivery BMI $\geqq 30 \mathrm{~kg} / \mathrm{m}^{2}$ was significantly associated with increased BMIs (adjusted 95\% Cl: 1.17 (0.72 to 1.63); $p<0.001$ ) and BMI percentiles (adjusted 95\% Cl: 23.48 (13.87 to 33.09); $p<0.001$ ) in their children. A maternal pre-delivery BMI of $27.16 \mathrm{~kg} / \mathrm{m}^{2}$ was the optimal cut-off for predicting offspring overweight/obesity at the age of 2 years.

Discussion. Our results indicate that the maternal pre-delivery BMI was significantly associated with offspring BMI and weight gain at the age of 2 years. A maternal pre-delivery BMI of $27.16 \mathrm{~kg} / \mathrm{m}^{2} \mathrm{might}$ be a useful predictor for estimating the risk of overweight or obesity in offspring at the age of 2 years. 
1 Article title

2 Association between maternal pre-delivery body mass index and offspring

3 overweight/obesity at 1 and 2 years of age among residents of a suburb in Taiwan

4

5 Hsien-Kuan Liu ${ }^{1}$, Chien-Yi Wu ${ }^{1}$, Yung-Ning Yang ${ }^{1}$, Pei-Ling Wu ${ }^{1}$, Zong-Rong He ${ }^{1}$, San-Nan

6 Yang $^{1}$, Shu-Leei Tey ${ }^{1, *}$

7

$8{ }^{1}$ Department of Pediatrics, E-Da Hospital, I-Shou University, Kaohsiung, Taiwan.

9

10

11

12

*Corresponding Author

13 Shu-Leei Tey

14 E-mail: djsr2000@hotmail.com

15

16

17

18 
20 Abstract:

21 Background. Overweight and obesity among children can cause metabolic syndrome in

22 adulthood and are a significant public health issue. Some studies suggest that maternal pre-

23 pregnancy body mass index (BMI) and excessive gestational weight gain during pregnancy are

24 associated with overweight and obesity in offspring. However, it is difficult to collect

25 information on accurate pre-pregnancy BMI and pregnancy weight gain for women living in

26 areas where medical resources are scarce. Maternal pre-delivery BMI might be predictive of the

27 risk of overweight and obesity among offspring of pregnant mothers living in suburban areas.

28 Methods. We retrospectively collected data on term neonates with appropriate weights for their

29 gestational age born between April 2013 and October 2015. We excluded neonates with major

30 congenital anomalies or diseases and incomplete data. Mothers with systemic diseases or drug

31 abuse were also excluded. Offspring body weights and heights at 1- and 2-years-old were

32 recorded. Maternal pre-delivery BMI was divided into following groups: $<25 \mathrm{~kg} / \mathrm{m}^{2}, 25-29.9$

$33 \mathrm{~kg} / \mathrm{m}^{2}$, and $\geqq 30 \mathrm{~kg} / \mathrm{m}^{2}$.

34 Results. We included 261 mother-child pairs in this study. The BMIs of the offspring differed

35 significantly among the 3 maternal pre-delivery BMI groups at the age of 2 years $(15.18 \pm 1.04$

$36 \mathrm{~kg} / \mathrm{m}^{2}, 15.83 \pm 1.28 \mathrm{~kg} / \mathrm{m}^{2}$, and $16.29 \pm 1.61 \mathrm{~kg} / \mathrm{m}^{2}, p<0.001$, respectively). After adjusting for 
37 potential cofounders possibly affecting weight using multivariate linear regression, the children's

38 BMIs (adjusted 95\% CI: 0.71 ( 0.31 to 1.11 ); $p=0.001$ ) and BMI percentiles (adjusted 95\% CI:

3915.80 ( 7.32 to 24.28$) ; p<0.001)$ at the age of 2 years were significantly higher in those born to

40 mothers with pre-delivery BMIs of $25-29.9 \mathrm{~kg} / \mathrm{m}^{2}$ compared to mothers with pre-delivery BMIs

$41<25 \mathrm{~kg} / \mathrm{m}^{2}$. Maternal pre-delivery BMI $\geqq 30 \mathrm{~kg} / \mathrm{m}^{2}$ was significantly associated with increased

42 BMIs (adjusted 95\% CI: 1.17 (0.72 to 1.63 ); $p<0.001$ ) and BMI percentiles (adjusted 95\% CI:

4323.48 (13.87 to 33.09); $p<0.001)$ in their children. A maternal pre-delivery BMI of $27.16 \mathrm{~kg} / \mathrm{m}^{2}$

44 was the optimal cut-off for predicting offspring overweight/obesity at the age of 2 years.

45 Discussion. Our results indicate that the maternal pre-delivery BMI was significantly associated

46 with offspring BMI and weight gain at the age of 2 years. A maternal pre-delivery BMI of 27.16

$47 \mathrm{~kg} / \mathrm{m}^{2}$ might be a useful predictor for estimating the risk of overweight or obesity in offspring at

48 the age of 2 years.

49 
Introduction

Overweight and obesity among children is a public health issue that can result in adult

metabolic syndrome (de Onis, Blössner \& Borghi, 2010; Kim, Lee \& Lim, 2017). There are many

factors associated with overweight/obesity in children, including early childhood lifestyle and sedentary behavior, dietary patterns, sleep patterns and durations, and parental body mass index

61 (BMI) (Reilly et al., 2005; Dev et al., 2013). The Developmental Origins of Health and Disease

62 (DOHaD) hypothesis, which proposed by Barker (Barker, 2007), expounded the high correlation

63 between maternal environment and their offspring. For the past few years, DOHaD hypothesis

64 had been broadly adapted in subsequent studies concerning early life environment influences the later onset of obesity (Wadhwa et al., 2009; Kappil, Wright \& Sanders, 2016). This concept has

66 enticed an increasing number of researchers to study the associations between maternal obesity

67 and their offspring's obesity (Guo et al., 2015; Wrotniak et al., 2008). During the gestational period, the maternal metabolic state can affect both maternal health and fetal growth, even predisposing the offspring to the development of metabolic disorders (Catalano \& Ehrenberg, 2006). As there may be a connection between maternal BMI and offspring health, this is a potentially useful means of predicting and preventing child overweight and obesity. 
72 The Institute of Medicine (IOM) of the National Academies proposed a recommendation of

73 appropriate gestational weight gain based on maternal pre-pregnancy BMI (Institute of Medicine

74 of the National Academies, 2009). Currently, studies have revealed that high pre-pregnancy BMI

75 and excessive gestational weight gain were associated with overweight/obesity in their offspring

76 (Li et al., 2013; Schack-Nielsen et al., 2010). In Taiwan, nearly all pregnant women deliver in a

77 metropolitan hospital or medical provision clinic. Therefore, maternal pre-pregnancy BMI or

78 gestational weight gain can be accessed easily during the pre-natal visits. However, for those

79 pregnant women living in suburbs where medical resources are scarce and prenatal care was

80 inadequate, it was difficult to collect accurate pre-pregnancy BMI and gestational weight gain

81 (Kisuule et al., 2013; Islam et al., 2017; Debessai et al., 2016; Fobelets et al., 2015). For these

82 women, and their future children, it became a priority to identify an alternate predictor of

83 overweight/obesity in their offspring.

84 Pre-delivery BMI, which can be obtained just prior to delivery, is an easier measurement to

85 obtain from pregnant women who lived in the suburbs. If a high pre-pregnancy BMI or excessive

86 gestational weight gain could cause adverse pregnancy outcomes and increased offspring body

87 weight later in life, then we considered that a high pre-delivery BMI might more or less have a

88 similar effect. To answer this question, we designed a study to compare the association between

89 maternal pre-delivery BMI and the BMI of the offspring at the ages of 1 and 2 years. Our goal 
90 for this study, therefore, was to find a new parameter to predict the risk of overweight and

91 obesity in the offspring of the pregnant mothers in the suburbs, and try to find out a cut-off point

92 of maternal pre-delivery BMI for predicting overweight and obesity in their offspring.

\section{Materials and methods}

\section{Study designs and subjects}

96 E-Da Hospital is located in Yanchao District (a suburb area in Kaohsiung), occupies 6300

97 hectares of land and has a population of about 29,000 people. Patients in the E-Da Hospital

98 mostly reside in the Yanchao District and the adjacent regions. Owing to the vast territory with

99 few residents, this district is a medical resource-limited area.

100 This was a retrospective cohort study. Both pregnant women and their children's health care

101 records from E-Da Hospital were collected. We collected 1753 records of both the delivering

102 mothers and their infants between April 2013 and October 2015. The children's health records

103 included the birth-related information (date of birth, sex, gestational weeks at time of birth, birth

104 weight, birth height, Apgar score, among others) and the infancy health examinations during the

105 first 24 months. Neonates who were preterm, post-term, small for GA (birth weight $<10$ th

106 percentile), large for GA (birth weight $>90$ th percentile), with presence of major congenital

107 anomalies, congenital disease, or incomplete data were excluded from this survey. 
108 Pregnant women's health records included general information (age, occupation, education,

109 number of pregnancies, smoking habits, among others), any history of diseases, all clinical

110 measurements (height, weight, gynecological examinations, ultrasonography, gestational

111 diabetes (GDM) screening test, and other lab tests), complications experienced during

112 pregnancy, and pregnancy outcomes (delivery modes, labor complications, placenta weight). The

113 pre-delivery BMI was calculated using the weight and height recorded upon admission for

114 delivery. BMIs were calculated by dividing the weight in kilograms by the square of the height

115 in meters. The pre-delivery BMI was categorized into 3 groups: $<25 \mathrm{~kg} / \mathrm{m}^{2}, 25-29.9 \mathrm{~kg} / \mathrm{m}^{2}$,

116 and $\geqq 30 \mathrm{~kg} / \mathrm{m}^{2}$. Mothers who were diabetic, or had pregnancy-induced hypertension, a history of

117 illegal substance abuse, human immunodeficiency virus infected, hyper- or hypothyroidism, or

118 incomplete medical records were all excluded.

119 This study included the information and clinical measurements of 261 mother-child pairs,

120 after excluding premature infants, post-term infants, congenital anomaly, small for gestational

121 age + large for gestational age, pregnancy-induced hypertension, GDM, GDM + pregnancy-

122 induced hypertension, maternal substance abuse, human immunodeficiency virus infected

123 mother, maternal hyper/hypothyrodism, and incomplete data of neonate and mother.

124 We obtained approval from the E-Da Hospital's Institutional Review Board

125 (EMRP02107N). All patient information was de-identified before analysis. 


\section{Assessment of infant body weight}

128 All infants had a preventative health visit for vaccinations at 1 year and 2 years of age

129 according to the Taiwan vaccination programs. Body weight, body height and health status were

130 recorded at every visit. No infants had acute illnesses at the vaccination health visits. The body

131 weights were measured with light clothing using a digital scale, and the body heights were

132 measured with bare feet using a recumbent length stadiometer. Weight gain was calculated as the

133 difference between the weight at birth and weight at 1 or 2 year of age. BMIs were calculated by

134 dividing the weight in kilograms by the square of the height in meters. The definition of children

135 obesity is according to new growth charts for Taiwanese children (Chen \& Chang, 2010). Those

136 with missing data on body weight at 1 year or 2 years of age were excluded.

\section{Statistical analysis}

139 Data were analyzed using SPSS statistical software version 20 (IBM Corp., Armonk, NY,

140 USA). Proportions are presented for categorical variables and means \pm standard deviations are

141 presented for continuous variables. The Chi-square test (for categorical variables) and Kruskal-

142 Wallis test were used for comparisons among three groups of maternal pre-delivery BMIs. We

143 conducted a multivariate linear regression to adjust the potential variables associated with 
144 outcomes including sex, mode of delivery, and maternal pre-delivery BMI. We report 95\%

145 confidence Intervals (CI) with $P$ values. Covariate variables were selected from among the

146 significant predictors $(p<0.05)$ between the 3 groups according to maternal pre-delivery BMI, as

147 well as by the use of clinical judgment. Statistical significance was defined as a $p$ value $<0.05$.

148 Receiver operating characteristic (ROC) curves were drawn to determine the optimal

149 threshold for predicting overweight and obesity in children at 2 years of age depending on

150 maternal pre-delivery BMI. The optimal threshold value was used as the cut-off point to

151 determine the sensitivity, specificity, and negative predictive values of maternal pre-delivery

152 BMI to detect overweight and obesity at 2 years of age.

\section{Results}

This study included the information and clinical measurements of 261 mother-child pairs,

158 after excluding premature infants $(n=314)$, post-term infants $(n=7)$, congenital anomaly $(n=9)$,

159 small for gestational age + large for gestational age $(\mathrm{n}=274)$, loss to follow up after discharge

$160(\mathrm{n}=84)$, pregnancy-induced hypertension $(\mathrm{n}=119), \mathrm{GDM}(\mathrm{n}=85), \mathrm{GDM}+$ pregnancy-induced

161 hypertension ( $\mathrm{n}=61)$, maternal substance abuse $(\mathrm{n}=3)$, human immunodeficiency virus infected 
162 mother $(\mathrm{n}=3)$, maternal hyper/hypothyrodism $(\mathrm{n}=18)$, and maternal incomplete data $(\mathrm{n}=7)($ Fig.

163 1). Among the 261 children, 137 (52.5\%) were boys. The mean gestational age was $38.97 \pm 0.99$

164 weeks, and the mean birth weight was $3.18 \pm 0.28$ kilograms. The participants were stratified

165 into 3 groups according to the maternal pre-delivery BMI $\left(<25 \mathrm{~kg} / \mathrm{m}^{2}, 25-29.9 \mathrm{~kg} / \mathrm{m}^{2}\right.$, and $\geqq 30$

$166 \mathrm{~kg} / \mathrm{m}^{2}$ ). The maternal and offspring demographic characteristics are presented in Table 1. The

167 overall overweight and obesity rates in children aged 1 and 2 years were $10.0 \%(26 / 261)$ and

$1689.2 \%(24 / 261)$, respectively. The rate of overweight/obesity showed no significant difference at 1

169 year of age in each maternal pre-delivery BMI category $(5 / 85(2.5 \%), 11 / 96(11.5 \%)$, and 10/63

$170(15.9 \%)$, respectively; $p=0.142)$. However, the rate differed significantly at 2 years of age $(2 / 79$

$171(2.5 \%), 10 / 85(11.8 \%)$, and 12/57 (21.1\%), respectively; $p=0.003)$. The infants birth weights

$172(3.08 \pm 0.25 \mathrm{~kg}, 3.24 \pm 0.28 \mathrm{~kg}$, and $3.22 \pm 0.27 \mathrm{~kg}$, respectively; $p=0.001)$ and birth BMIs

$173\left(12.29 \pm 0.90 \mathrm{~kg} / \mathrm{m}^{2}, 12.62 \pm 1.02 \mathrm{~kg} / \mathrm{m}^{2}\right.$, and $12.76 \pm 1.00 \mathrm{~kg} / \mathrm{m}^{2}$, respectively; $\left.p=0.002\right)$ were

174 significantly higher in children whose maternal pre-delivery BMIs were $\geq 25 \mathrm{~kg} / \mathrm{m}^{2}$ than in those

175 whose maternal pre-delivery BMIs were $<25 \mathrm{~kg} / \mathrm{m}^{2}$. Our results also revealed that 56 infants

176 were delivered by Cesarean section (21.5\%). The rate of Cesarean section differed significantly

177 in each maternal pre-delivery BMI category (10/90 (11.1\%), 27/105 (25.7\%), and 19/66 (28.8\%),

178 respectively; $p=0.011$ ). The overweight and obesity rates at 1 year showed no significant

179 association among the 3 groups $(p=0.142)$, whereas it differed significantly at 2 years $(p=0.003)$. 

$p=0.005)$. The children BMI percentile $(45.94 \pm 25.68,52.00 \pm 25.54$, and $60.07 \pm 25.76$, respectively) and weight gain $(6.21 \pm 0.87,6.32 \pm 0.78$, and $6.60 \pm 0.99$, respectively) at age 1

BMI groups $\left(15.18 \pm 1.04 \mathrm{~kg} / \mathrm{m}^{2}, 15.83 \pm 1.28 \mathrm{~kg} / \mathrm{m}^{2}\right.$, and $16.29 \pm 1.61 \mathrm{~kg} / \mathrm{m}^{2}$, respectively; age 2 years showed a significant association among the 3 groups $(p<0.001$ and $p=0.004)$ (Table

\section{at ages 1 and 2 years of age}

197 body weights at 1 and 2 years of age (sex, mode of delivery, and maternal pre-delivery BMI). 
198 The resulting multivariate linear regression analyses are presented in Table 3. At 1 year of age,

199 BMIs $(p<0.001)$, BMI percentiles $(p=0.001)$, and weight gain $(p=0.015)$ were significantly

200 higher in children born to mothers with pre-delivery BMIs of $\geqq 30 \mathrm{~kg} / \mathrm{m}^{2}$ compared to those

201 born to mothers with pre-delivery BMIs of $<25 \mathrm{~kg} / \mathrm{m}^{2}$. At 2 years of age, BMIs $(p=0.001)$ and

202 BMI percentiles $(p<0.001)$ were significantly higher in children born to mothers with pre-

203 delivery BMIs of $25-29.9 \mathrm{~kg} / \mathrm{m}^{2}$ compared to those born to mothers with pre-delivery BMIs of $<$

$20425 \mathrm{~kg} / \mathrm{m}^{2}$. Similarly, maternal pre-delivery BMI $\geqq 30 \mathrm{~kg} / \mathrm{m}^{2}$ was also significantly associated

205 with an increase in the children's BMIs, BMI percentiles, and weight gain (all $p<0.001)$ at 2

206 years of age (Table 3).

207

208 Diagnostic value of maternal pre-delivery BMI for predicting their offspring's

overweight/obesity

210

The relative contributor of explanatory variables to offspring overweight/obesity at 2 year

211 of age were analyzed (Table 4). Among these variables, pre-delivery BMI remained a significant

212 risk factors that would contribute offspring overweight/obesity at 2 year of age (OR:1.206, 95\%

213 CI: $1.10-1.33 ; p<0.001)$. Children overweight/obesity at 1 year of age was another risk factor

214 (OR:2.680) but this factor was not significant $(p=0.082)$. In addition, the ROC curves of

215 maternal pre-delivery BMI for predicting offspring overweight/obesity at 2 years is shown in 
216 Fig. 2. The area under the ROC curve (AUROC) was $0.750(95 \%$ CI: $0.654-0.847 ; p<0.001)$ for

217 diagnosing the offspring with overweight/obesity at 2 years, according to new growth charts for

218 Taiwanese children (Chen \& Chang, 2010). The optimal cut-off point (by Youden index) for

219 maternal pre-delivery BMI to detect their offspring's overweight/obesity at 2 years was 27.16

$220 \mathrm{~kg} / \mathrm{m}^{2}$, with a negative predictive value (NPV) of $96.69 \%$, a sensitivity of $83.3 \%$, and a

221 specificity of 59.4\%. We also transformed the continuous variable of maternal pre-delivery BMI

222 into categorical variable by this cutoff point. The odd ratios of maternal pre-delivery BMI >

$22327.16 \mathrm{~kg} / \mathrm{m}^{2}$ was 7.312 (95\%CI: $\left.2.41-22.20 ; p<0.001\right)$ (Table 4).

225 Discussion

226 Many studies have shown that both higher maternal pre-pregnancy BMI and greater

227 gestational weight gain are associated with increased BMIs in early childhood (Li et al., 2013;

228 Schack-Nielsen et al., 2010). There are few studies that have evaluated the correlation between

229 maternal pre-delivery BMI and offspring obesity. This study indicated that maternal pre-delivery

230 BMI might also predict the risk of children developing overweight/obesity later in life. We found

231 that the maternal pre-delivery BMI was linearly associated with the BMI of children aged 1-2

232 years even after adjustment for birth weight, sex, and mode of delivery. We also noticed that the 
233 risk of childhood overweight was highest among the mothers whose pre-delivery BMI was $\geqq 30$

$234 \mathrm{~kg} / \mathrm{m}^{2}$.

235 In recent years, some studies have reported that greater maternal pre-pregnancy BMIs may

236 have an impact on the childhood body weights in their offspring (Yu et al., 2013; Xiong et al.,

237 2016). Our results showed similar results to these studies. We found that women with higher pre-

238 delivery BMIs were associated with higher risks for Cesarean section, higher birth weight babies,

239 and an increased risk of offspring with overweight/obesity in the first two years of life. There are

240 a couple of advantages with using maternal pre-delivery BMI. First, maternal pre-delivery BMI

241 can be obtained easily before delivery and can be applied in all medical facilities, even in areas

242 with limited medical resources. Second, recall errors and biases associated with pre-pregnancy

243 BMI could be avoided by using the pre-delivery BMI.

244 There are a number of possible mechanisms responsible for the association between

245 maternal pre-delivery BMI and overweight in their offspring. The Developmental Origins of

246 Health and Disease (DOHaD) hypothesis, also called the "Barker hypothesis", proposed by

247 Barker and colleagues, could explain this relationship (Barker, 2007; Armitage, Poston \&

248 Taylor, 2008; Zheng et al., 2014). According to this hypothesis, the energy excess in the

249 maternal diet causes the accumulation of excess adipose tissue, which might modify DNA

250 methylation and gene expression in their offspring (Zheng et al., 2014; Morales et al., 2014). 
251 This methylation process could result in offspring adiposity (Godfrey et al., 2011). This theory

252 indicates that high maternal pre-delivery BMI might play an important role in offspring

253 overweight and might contribute to the overweight epidemic among infants and children.

254 Historically, there has been an emphasis on promoting sufficient weight gain during

255 pregnancy in an effort to reduce low-birth weight deliveries and adverse perinatal outcomes. In

256 2009, the IOM published new recommendations for weight gain during pregnancy (Institute of

257 Medicine of the National Academies, 2009). However, obesity rather than insufficient weight

258 gain during pregnancy became a more common problem nowadays. Between 1997 and 2007,

259 approximately $46 \%$ of pregnant women in the US gained more weight than the IOM

260 recommended. Additional studies showed that maternal pre-pregnancy obesity and excessive

261 gestational weight gain (GWG) were associated with greater risks of future offspring obesity.

262 Nevertheless, the recommended gestational weight gain might not be suitable for reproductive-

263 aged women in different countries due to variations in body physique or body composition,

264 which differed from race and ethnicity (Wagner \& Heyward, 2000). Yang et al. investigated the

265 recommended gestational weight gain for Chinese women as recommended by the IOM, and

266 they found that the gestational weight gain suggested by the IOM might not be helpful for

267 Chinese women (Yang et al., 2015). In our study, we found that maternal pre-delivery BMI 27.16

$268 \mathrm{~kg} / \mathrm{m}^{2}$ was a reliable cut-off value for predicting offspring overweight/obesity at 2 years of age in 
269 Chinese reproductive-aged women with an odd ratio of 7.312. High negative predictive value of

270 this cut-off point can offer us a guide to educate the mother to control their BMI before delivery.

271 If the mother can control their pre-delivery BMI less than $27.16 \mathrm{~kg} / \mathrm{m}^{2}$, there will be a $96.69 \%$

272 chance that their offspring will not have overweight/obesity at 2 years of age. In addition,

273 maternal pre-delivery BMI is easier to assess than GWG for pregnant women residing in the

274 suburbs of Taiwan.

275 There are several strengths in our study. The pre-delivery BMI can be measured easily and

276 accurately despite the different scales of medical facilities and can even be easily measured in

277 medical resource-limited hospitals. Furthermore, this measurement would not be affected by

278 irregular or delayed prenatal care. Thus, potential misreporting and participation bias with

279 respect to the pre-pregnant BMI can be avoided. There are also some limitations in our study.

280 First, this was a retrospective study, so it is possible that selection bias could have influenced our

281 results. However, this issue was minimized by stratifying the groups according to maternal pre-

282 delivery BMIs and adjusting the possible confounding factors in this study. Second, although we

283 created multivariable models to adjust for the potential confounders, the sample size of this study

284 was still small and the participants were from a single hospital located in southern Taiwan. Thus,

285 the study result may not be generalizable to other countries or other ethnicities. Third, there are

286 still a few possible confounders that we were not able to adjust for, including childhood nutrition 
287 and physical activity. Our sample population was mainly from a suburb where the lifestyle

288 factors are similar, so these effects are expected to be small. Last, a large number of cases were

289 excluded due to incomplete data. However, the basal characteristics of maternal and offspring we

290 excluded was not significantly different than those enrolling participants, suggesting that this

291 limitation may not have introduced a significant selection bias (Supplementary Table).

292 Our hospital is located in a suburb area in Taiwan, and also, is the largest hospital nearby.

293 Some infants would receive their regular health examination and vaccine administration in the

294 local clinic instead of our hospital after birth. Therefore, anthropometric measurement and

295 healthy status of participants could not be obtained due to loss following up. With these

296 incomplete data, the result might not be generalized. A further large-scale study may minimize

297 this bias.

298

299 Conclusion

300 In conclusion, this study result indicates that maternal pre-delivery BMI might be a new

301 parameter to predict the risk of overweight and obesity among the offspring of pregnant mothers

302 in a suburb of Taiwan. Furthermore, the maternal pre-delivery BMI value of $27.16 \mathrm{~kg} / \mathrm{m}^{2}$ may

303 suggest a useful predictor when estimating the offspring's risk of overweight or obesity at age 2 
304 years. These findings indicate that more attention needs to be paid to infants of mothers with

305 higher pre-delivery BMIs, especially those $\geqq 27.16 \mathrm{~kg} / \mathrm{m}^{2}$.

306

307

308

309 Acknowledgments

310 The authors are grateful to Chun-Hua Yang and Tzu-Shan Chen, who were consultants on

311 statistical methods in this study.

312

313 References

314 Armitage JA, Poston L, Taylor PD. 2008. Developmental origins of obesity and the metabolic

315 syndrome: the role of maternal obesity. Front Horm Res 36:73-84. DOI: 10.1159/0000115355.

316 Barker DJ. 2007. The origins of the developmental origins theory. J Intern Med 261:412-417.

317 Catalano PM, Ehrenberg HM. 2006. The short- and long-term implications of maternal obesity

318 on the mother and her offspring. BJOG 113:1126-1133.

319 Chen W, Chang MH. 2010. New growth charts for Taiwanese children and adolescents based

320 on World Health Organization standards and health-related physical fitness. Pediatr Neonatol

321 51:69-79. DOI: 10.1016/S1875-9572(10)60014-9. 
322 Debessai Y, Costanian C, Roy M, El-Sayed M, Tamim H. 2016. Inadequate prenatal care use

323 among Canadian mothers: findings from the Maternity Experiences Survey. J Perinatol 36:420-

324 426. DOI: $10.1038 /$ jp.2015.218.

325 de Onis M, Blössner M, Borghi E. 2010. Global prevalence and trends of overweight and

326 obesity among preschool children. Am J Clin Nutr 92:1257-1264. DOI:

327 10.3945/ajen.2010.29786.

328 Dev DA, McBride BA, Fiese BH, Jones BL, Cho H; Behalf of The Strong Kids Research

329 Team. 2013. Risk factors for overweight/obesity in preschool children: an ecological approach.

330 Child Obes 9:399-408. DOI: 10.1089/chi.2012.0150

331 Fobelets M, Beeckman K, Hoogewys A, Embo M, Buyl R, Putman K. 2015. Predictors of late

332 initiation for prenatal care in a metropolitan region in Belgium. A cohort study. Public Health

333 129:648-654. DOI: 10.1016/j.puhe.2015.03.008.

334 Godfrey KM, Sheppard A, Gluckman PD, Lillycrop KA, Burdge GC, McLean C, Rodford

335 J, Slater-Jefferies JL, Garratt E, Crozier SR, Emerald BS, Gale CR, Inskip HM, Cooper C,

336 Hanson MA. 2011. Epigenetic gene promoter methylation at birth is associated with child's later

337 adiposity. Diabetes 60:1528-1534. DOI: 10.2337/db10-0979.

338 Guo L, Liu J, Ye R, Liu J, Zhuang Z, Ren A. 2015. Gestational weight gain and overweight in

339 children aged 3-6 years. J Epidemiol 25:536-543. DOI: 10.2188/jea.JE20140149. 
340 Institute of Medicine (US) and National Research Council (US) Committee to Reexamine

341 IOM Pregnancy Weight Guidelines; Rasmussen KM, Yaktine AL, editors. 2009. Weight

342 Gain During Pregnancy: Reexamining the Guidelines. Washington (DC): National Academies

343 Press (US)

344 Islam MJ, Broidy L, Baird K, Mazerolle P. 2017. Exploring the associations between intimate

345 partner violence victimization during pregnancy and delayed entry into prenatal care: Evidence

346 from a population-based study in Bangladesh. Midwifery 47:43-52. DOI:

347 10.1016/j.midw.2017.02.002.

348 Kappil M, Wright RO, Sanders AP. 2016. Developmental origins of common disease:

349 epigenetic contributions to obesity. Annu Rev Genomics Hum Genet 17:177-192. DOI:

350 10.1146/annurev-genom-090314-050057.

351 Kim J, Lee I, Lim S. 2017. Overweight or obesity in children aged 0 to 6 and the risk of adult

352 metabolic syndrome: A systematic review and meta-analysis. J Clin Nurs 26:3869-3880. DOI:

353 10.1111/jocn.13802.

354 Kisuule I, Kaye DK, Najjuka F, Ssematimba SK, Arinda A, Nakitende G, Otim L. 2013.

355 Timing and reasons for coming late for the first antenatal care visit by pregnant women at

356 Mulago hospital, Kampala Uganda. BMC Pregnancy Childbirth 13:121. DOI: 10.1186/1471-

357 2393-13-121. 
358 Li N, Liu E, Guo J, Pan L, Li B, Wang P, Liu J, Wang Y, Liu G, Hu G. 2013. Maternal

359 prepregnancy body mass index and gestational weight gain on offspring overweight in early

360 infancy. PLoS One 8:e77809. DOI: 10.1371/journal.pone.0077809.

361 Morales E, Groom A, Lawlor DA, Relton CL. 2014. DNA methylation signatures in cord

362 blood associated with maternal gestational weight gain: results from the ALSPAC cohort. $B M C$

363 Res Notes 7:278. DOI: 10.1186/1756-0500-7-278.

364 Rahman M, Temple JR, Breitkopf CR, Berenson AB. 2009. Racial differences in body fat

365 distribution among reproductive-aged women. Metabolism 58:1329-37. DOI:

366 10.1016/j.metabol.2009.04.017.

367 Reilly JJ1, Armstrong J, Dorosty AR, Emmett PM, Ness A, Rogers I, Steer C, Sherriff A;

368 Avon Longitudinal Study of Parents and Children Study Team. 2005. Early life risk factors

369 for obesity in childhood: cohort study. BMJ 330:1357.

370 Schack-Nielsen L, Michaelsen KF, Gamborg M, Mortensen EL, Sørensen TI. 2010.

371 Gestational weight gain in relation to offspring body mass index and obesity from infancy

372 through adulthood. Int J Obes (Lond) 34:67-74. DOI: 10.1038/ijo.2009.206.

373 Wadhwa PD, Buss C, Entringer S, Swanson JM. 2009. Developmental origins of health and

374 disease: brief history of the approach and current focus on epigenetic mechanisms. Semin Reprod

375 Med. 27:358-68. DOI: 10.1055/s-0029-1237424. 
376 Wagner DR, Heyward VH. 2000. Measures of body composition in blacks and whites: a

377 comparative review. Am J Clin Nutr 71:1392-402.

378 Wrotniak BH, Shults J, Butts S, Stettler N. 2008. Gestational weight gain and risk of

379 overweight in the offspring at age $7 \mathrm{y}$ in a multicenter, multiethnic cohort study. Am J Clin Nutr

$380 \quad 87: 1818-1824$.

381 Xiong C, Zhou A, Cao Z, Zhang Y, Qiu L, Yao C, Wang Y, Zhang B. 2016. Association of

382 pre-pregnancy body mass index, gestational weight gain with cesarean section in term deliveries

383 of China. Sci Rep 6:37168. DOI: 10.1038/srep37168.

384 Yang S, Peng A, Wei S, Wu J, Zhao J, Zhang Y, Wang J, Lu Y, Yu Y, Zhang B. 2015.

385 Pre-pregnancy body mass index, gestational weight gain, and birth weight: a cohort study in

386 China. PLoS One 10:e0130101. DOI: 10.1371/journal.pone.0130101.

387 Yu Z, Han S, Zhu J, Sun X, Ji C, Guo X. 2013. Pre-pregnancy body mass index in relation to

388 infant birth weight and offspring overweight/obesity: a systematic review and meta-analysis.

389 PLoS One 8:e61627. DOI: 10.1371/journal.pone.0061627.

390 Zheng J, Xiao X, Zhang Q, Yu M. 2014. DNA methylation: the pivotal interaction between

391 early-life nutrition and glucose metabolism in later life. Br J Nutr 112:1850-1857. DOI:

$39210.1017 / \mathrm{S} 0007114514002827$. 
397 Legends

398 Figure 1. Participants' selection after excluding neonatal and maternal factors from 1753

399 neonates.

400

401 Figure 2. ROC curve of maternal pre-delivery body mass index for predicting offspring obesity

402 at 2 years of age.

403

404 Table 1. Baseline maternal and offspring demographic characteristics according to pre-delivery

405 maternal body mass index (BMI)

406

407 Table 2. Offspring weight index at 1 and 2 years of age according to maternal pre-delivery body

408 mass index (BMI)

409

410 Table 3. Multivariable linear regression for factors associated with offspring body weight

411 parameters at 1 and 2 years of age 
412

413 Table 4. Risk factors associated to children overweight/obesity at 2 years of age

414

415

416 Supplementary Table. Comparison of baseline maternal and offspring demographic

417 characteristics according to pre-delivery maternal body mass index (BMI) between the included

418 and excluded group 


\section{Table $\mathbf{1}$ (on next page)}

Baseline maternal and offspring demographic characteristics according to pre-delivery maternal body mass index (BMI) 
1 Table 1. Baseline maternal and offspring demographic characteristics according to pre-

2 delivery maternal body mass index (BMI)

\begin{tabular}{cccc}
\hline \hline & \multicolumn{3}{c}{ BMI } \\
\cline { 2 - 3 } & $<25 \mathrm{~kg} / \mathrm{m}^{2}$ & $25-29.9 \mathrm{~kg} / \mathrm{m}^{2}$ & $\geqq 30 \mathrm{~kg} / \mathrm{m}^{2}$ \\
$(\mathrm{n}=90)$ & $(\mathrm{n}=105)$ & $(\mathrm{n}=66)$ & \\
\hline
\end{tabular}

\section{Maternal demographics}

Maternal age

$<35$ years old

$\geqq 35$ years old

Placenta weight

Parity

Primipara

Multipara

$\begin{array}{ccr}74(82.2 \%) & 77(73.3 \%) & 48(72.7 \%) \\ 16(17.8 \%) & 28(26.7 \%) & 18(27.3 \%) \\ 653.70 \pm 151.95 & 663.23 \pm 135.42 & 654.67 \pm 116.97 \\ 48(53.3 \%) & 66(62.9 \%) & 38(57.6 \%) \\ 42(46.7 \%) & 39(37.1 \%) & 28(42.4 \%)\end{array}$

0.257

\section{Offspring demographics}

Gestational age (days)

$\begin{array}{rrr}39.02 \pm 0.92 & 39.01 \pm 0.99 & 38.81 \pm 1.07 \\ 3.08 \pm 0.25 & 3.24 \pm 0.28 & 3.22 \pm 0.27 \\ 12.29 \pm 0.90 & 12.62 \pm 1.02 & 12.76 \pm 1.00 \\ & & \\ 46(51.1 \%) & 51(48.6 \%) & 40(60.6 \%) \\ 44(48.9 \%) & 54(51.4 \%) & 26(39.4 \%)\end{array}$

Birth weight (kg)

Birth BMI $\left(\mathrm{kg} / \mathrm{m}^{2}\right)$

Sex

Boy

$44(48.9 \%)$

$54(51.4 \%)$

0.549

0.402

Mode of delivery

Vaginal

$80(88.9 \%)$

$78(74.3 \%)$

0.011

Cesarean section

$10(11.1 \%)$

$27(25.7 \%)$

$47(71.2 \%)$

Apgar score

1 minute

$7.97 \pm 0.18$

$7.92 \pm 0.49$

$7.82 \pm 0.89$

0.891

5 minutes

$8.98 \pm 0.15$

$8.95 \pm 0.35$

$8.81 \pm 0.58$

0.824

Data collected

1-year-old (days) ${ }^{\mathrm{a}}$

$380.10 \pm 31.43$

$377.51 \pm 23.08$

$377.93 \pm 15.67$

0.222

2-year-old (days) ${ }^{\mathrm{b}}$

$820.32 \pm 48.43$

$816.68 \pm 51.11$

$813.59 \pm 45.99$

0.319

1-year-old body type ${ }^{a}$

Normal

$80(94.1 \%)$

$85(88.5 \%)$

$53(84.1 \%)$

0.142

Overweight + Obesity

$5(5.9 \%)$

$11(11.5 \%)$

$10(15.9 \%)$

2-year-old body type

Normal 


$\begin{array}{llll}\text { Overweight }+ \text { Obesity } & 2(2.5 \%) & 10(11.8 \%) & 12(21.1 \%)\end{array}$

3 Data are presented as means \pm standard deviations or as numbers (proportion)

$4 \quad * p$ values were analyzed using the Kruskal-Wallis (for continuous variables) and Chi-square tests

5 (for categorical variables)

6 aTotal 244 participants were enrolled in the analysis at 1 year of age

7 bTotal 221 participants were enrolled in the analysis at 2 years of age 


\section{Table 2(on next page)}

Offspring weight index at 1 and 2 years of age according to maternal pre-delivery body mass index (BMI) 
Table 2. Offspring weight index at 1 and 2 years of age according to maternal pre-delivery body mass index (BMI)

\begin{tabular}{|c|c|c|c|c|}
\hline \multirow[b]{2}{*}{1 year old $^{a}$} & \multicolumn{3}{|c|}{ Maternal pre-delivery BMI } & \multirow[t]{2}{*}{$p^{*}$} \\
\hline & $<25 \mathrm{~kg} / \mathrm{m}^{2}(\mathrm{n}=85)$ & $25-29.9 \mathrm{~kg} / \mathrm{m}^{2}(\mathrm{n}=96)$ & $\geqq 30 \mathrm{~kg} / \mathrm{m}^{2}(\mathrm{n}=63)$ & \\
\hline BW (kg) & $9.31 \pm 0.91$ & $9.55 \pm 0.87$ & $9.83 \pm 1.03$ & 0.007 \\
\hline BH (cm) & $75.36 \pm 2.74$ & $75.66 \pm 2.58$ & $75.60 \pm 2.35$ & 0.861 \\
\hline BMI $\left(\mathrm{kg} / \mathrm{m}^{2}\right)$ & $16.37 \pm 1.15$ & $16.67 \pm 1.11$ & $17.19 \pm 1.61$ & 0.005 \\
\hline BMI percentile & $45.94 \pm 25.68$ & $52.00 \pm 25.54$ & $60.07 \pm 25.76$ & 0.006 \\
\hline Weight gain ${ }^{\mathrm{b}}(\mathrm{kg})$ & $6.21 \pm 0.87$ & $6.32 \pm 0.78$ & $6.60 \pm 0.99$ & 0.044 \\
\hline 2 years old & $<25 \mathrm{~kg} / \mathrm{m}^{2}(\mathrm{n}=79)$ & $25-29.9 \mathrm{~kg} / \mathrm{m}^{2}(\mathrm{n}=85)$ & $\geqq 30 \mathrm{~kg} / \mathrm{m}^{2}(\mathrm{n}=57)$ & \\
\hline BW (kg) & $12.04 \pm 1.19$ & $12.31 \pm 1.39$ & $12.93 \pm 1.62$ & 0.004 \\
\hline BH (cm) & $88.80 \pm 3.12$ & $88.25 \pm 3.08$ & $89.12 \pm 3.16$ & 0.461 \\
\hline BMI $\left(\mathrm{kg} / \mathrm{m}^{2}\right)$ & $15.18 \pm 1.04$ & $15.83 \pm 1.28$ & $16.29 \pm 1.61$ & $<0.001$ \\
\hline BMI percentile & $35.24 \pm 24.74$ & $49.86 \pm 27.72$ & $56.68 \pm 29.97$ & $<0.001$ \\
\hline $\begin{array}{l}\text { Weight gain }{ }^{d} \\
\text { (kg) }\end{array}$ & $8.90 \pm 1.13$ & $9.12 \pm 1.29$ & $9.72 \pm 1.57$ & 0.004 \\
\hline
\end{tabular}

${ }^{*} p$ value was analyzed by Kruskal-Wallis test

aTotal 244 participants were enrolled in the analysis at 1 year of age

4 bThe weight difference between birth and 1 year of age

$5{ }^{c}$ Total 221 participants were enrolled in the analysis at 2 years of age

6 dThe weight difference between birth and 2 years of age

7 BW: body weight; BH: body height; BMI: body mass index 


\section{Table 3(on next page)}

Multivariable linear regression for factors associated with offspring body weight parameters at 1 and 2 years of age 
1 Table 3. Multivariable linear regression for factors associated with offspring body weight

2 parameters at 1 and 2 years of age

\begin{tabular}{|c|c|c|c|c|}
\hline \multicolumn{5}{|c|}{ 1-year-old $(n=244)$} \\
\hline \multirow{2}{*}{$\begin{array}{l}\text { BMI } \\
\text { Variables }\end{array}$} & \multicolumn{2}{|l|}{ Crude } & \multicolumn{2}{|l|}{ Adjusted } \\
\hline & $B(95 \% \mathrm{CI})$ & $P$ & $B(95 \% \mathrm{CI})$ & $p$ \\
\hline Sex & $0.32(-0.01$ to 0.65$)$ & 0.053 & $0.28(-0.05$ to 0.60$)$ & 0.092 \\
\hline Mode of delivery & $0.11(-0.29$ to 0.51$)$ & 0.578 & $-0.00(-0.40$ to 0.39$)$ & 0.987 \\
\hline \multicolumn{5}{|c|}{ Maternal pre-delivery } \\
\hline \multicolumn{5}{|l|}{$\mathrm{BMI}^{\dagger}$} \\
\hline $25-29.9 \mathrm{~kg} / \mathrm{m}^{2}$ & $0.17(-0.39$ to 0.29$)$ & 0.769 & $0.31(-0.07$ to 0.68$)$ & 0.109 \\
\hline$\geqq 30 \mathrm{~kg} / \mathrm{m}^{2}$ & $0.19(0.29$ to 1.03$)$ & $<0.001$ & $0.80(0.37$ to 1.23$)$ & $<0.001$ \\
\hline BMI percentile & \multicolumn{2}{|l|}{ Crude } & \multicolumn{2}{|l|}{ Adjusted } \\
\hline Variables & $B(95 \% \mathrm{CI})$ & $P$ & $B(95 \% \mathrm{CI})$ & $p$ \\
\hline Sex & $-2.55(-9.14$ to 4.05$)$ & 0.448 & $-3.34(-9.88$ to 3.17$)$ & 0.312 \\
\hline Mode of delivery & $3.50(-4.49$ to 11.49$)$ & 0.389 & $1.32(-6.72$ to 9.35$)$ & 0.747 \\
\hline \multicolumn{5}{|c|}{ Maternal pre-delivery } \\
\hline \multicolumn{5}{|l|}{$\mathrm{BMI}^{\dagger}$} \\
\hline $25-29.9 \mathrm{~kg} / \mathrm{m}^{2}$ & 3.43 (-6.71 to 6.80$)$ & 0.989 & $5.80(-1.81$ to 13.42$)$ & 0.134 \\
\hline$\geqq 30 \mathrm{~kg} / \mathrm{m}^{2}$ & 3.76 (3.50 to 18.32$)$ & 0.004 & 14.35 (5.72 to 22.97$)$ & 0.001 \\
\hline Weight gain & \multicolumn{2}{|l|}{ Crude } & \multicolumn{2}{|l|}{ Adjusted } \\
\hline Variables & $B(95 \% \mathrm{CI})$ & $P$ & $B(95 \% \mathrm{CI})$ & $p$ \\
\hline Sex & $0.36(0.14$ to 0.58$)$ & 0.001 & $0.34(0.12$ to 0.55$)$ & 0.003 \\
\hline Mode of delivery & $0.06(-0.21$ to 0.33$)$ & 0.675 & $0.01(-0.26$ to 0.28$)$ & 0.943 \\
\hline \multicolumn{5}{|c|}{ Maternal pre-delivery } \\
\hline \multicolumn{5}{|l|}{$\mathrm{BMI}^{\dagger}$} \\
\hline $25-29.9 \mathrm{~kg} / \mathrm{m}^{2}$ & $0.12(-0.29$ to 0.17$)$ & 0.608 & $0.11(-0.14$ to 0.37$)$ & 0.379 \\
\hline$\geqq 30 \mathrm{~kg} / \mathrm{m}^{2}$ & $0.13(0.08$ to 0.59$)$ & 0.010 & $0.36(0.07$ to 0.65$)$ & 0.015 \\
\hline
\end{tabular}

2-year-old $(\mathrm{n}=221)$

\begin{tabular}{lcccc}
\hline BMI & \multicolumn{1}{c}{ Crude } & \multicolumn{2}{c}{ Adjusted } \\
\hline Variables & $B(95 \% \mathrm{CI})$ & $P$ & $B(95 \% \mathrm{CI})$ & $p$ \\
\hline Sex & $0.20(-0.16$ to 0.56$)$ & 0.283 & $0.14(-0.20$ to 0.49$)$ & 0.413 \\
Mode of delivery & $-0.12(-0.56$ to 0.33$)$ & 0.606 & $-0.32(-0.74$ to 0.11$)$ & 0.145 \\
Maternal pre-delivery & & & & \\
BMI $^{\dagger}$ & & & & \\
$\quad 25-29.9 \mathrm{~kg} / \mathrm{m}^{2}$ & $0.19(-0.19$ to 0.55$)$ & 0.337 & $0.71(0.31$ to 1.11$)$ & 0.001
\end{tabular}




\begin{tabular}{|c|c|c|c|c|}
\hline$\geqq 30 \mathrm{~kg} / \mathrm{m}^{2}$ & 0.21 (0.37 to 1.18$)$ & $<0.001$ & $1.17(0.72$ to 1.63$)$ & $<0.001$ \\
\hline BMI percentile & \multicolumn{2}{|l|}{ Crude } & \multicolumn{2}{|l|}{ Adjusted } \\
\hline Variables & $B(95 \% \mathrm{CI})$ & $P$ & $B(95 \% \mathrm{CI})$ & $P$ \\
\hline Sex & $-2.21(-9.81$ to 5.39$)$ & 0.567 & $-3.19(-10.45$ to 4.08$)$ & 0.388 \\
\hline Mode of delivery & $-2.58(-11.82$ to 6.66$)$ & 0.583 & $-6.80(-15.75$ to 2.15$)$ & 0.136 \\
\hline \multicolumn{5}{|c|}{ Maternal pre-delivery } \\
\hline \multicolumn{5}{|l|}{$\mathrm{BMI}^{\dagger}$} \\
\hline $25-29.9 \mathrm{~kg} / \mathrm{m}^{2}$ & $5.59(-2.12$ to 13.30$)$ & 0.154 & $15.80(7.32$ to 24.28$)$ & $<0.001$ \\
\hline$\geqq 30 \mathrm{~kg} / \mathrm{m}^{2}$ & $13.96(5.42$ to 22.49$)$ & 0.001 & 23.48 (13.87 to 33.09$)$ & $<0.001$ \\
\hline Weight gain & \multicolumn{2}{|l|}{ Crude } & \multicolumn{2}{|l|}{ Adjusted } \\
\hline Variables & $B(95 \% \mathrm{CI})$ & $P$ & $B(95 \% \mathrm{CI})$ & $p$ \\
\hline Sex & $0.27(-0.09$ to 0.62$)$ & 0.143 & $0.21(-0.14$ to 0.55$)$ & 0.239 \\
\hline Mode of delivery & $-0.42(-0.85$ to 0.02$)$ & 0.060 & $-0.55(-0.97$ to -0.12$)$ & 0.012 \\
\hline \multicolumn{5}{|c|}{ Maternal pre-delivery } \\
\hline \multicolumn{5}{|l|}{$\mathrm{BMI}^{\dagger}$} \\
\hline $25-29.9 \mathrm{~kg} / \mathrm{m}^{2}$ & $-0.12(-0.49$ to 0.24$)$ & 0.503 & $0.32(-0.09$ to 0.72$)$ & 0.124 \\
\hline$\geqq 30 \mathrm{~kg} / \mathrm{m}^{2}$ & 0.72 (0.32 to 1.12$)$ & 0.001 & 0.92 (0.46 to 1.38$)$ & $<0.001$ \\
\hline
\end{tabular}

$4 \nmid$ Maternal pre-delivery BMI was grouped as follows: $<25 \mathrm{~kg} / \mathrm{m}^{2}, 25-29.9 \mathrm{~kg} / \mathrm{m}^{2}$, and $\geqq 30 \mathrm{~kg} / \mathrm{m}^{2}$;

5 the reference category is $<25 \mathrm{~kg} / \mathrm{m}^{2}$

6 "Co-variables included in the linear regression analysis: birth weight, sex, mode of delivery, and 7 maternal pre-delivery body mass index 


\section{Table 4(on next page)}

Risk factors associated to children overweight/obesity at 2 years of age 
1 Table 4. Risk factors associated to children overweight/obesity at 2 years of age

\begin{tabular}{lccc}
\hline \hline Variable & OR & $95 \%$ CI & $P$ value \\
\hline Maternal pre-delivery BMI & 1.206 & $1.10-1.33$ & $<0.001$ \\
Maternal pre-delivery BMI $\left(>27.16 \mathrm{~kg} / \mathrm{m}^{2} /<27.16\right.$ & 7.312 & $2.41-22.20$ & $<0.001$ \\
$\left.\mathrm{~kg} / \mathrm{m}^{2}\right)^{\mathrm{a}}$ & & & \\
Children sex (male/female) & 1.304 & $0.55-3.08$ & 0.545 \\
Mode of delivery (Cesarean section / Vaginal & 0.738 & $0.24-2.28$ & 0.597 \\
delivery) & & & \\
Overweight/obesity at 1 year of age & 2.680 & $0.88-8.13$ & 0.082 \\
\hline \hline
\end{tabular}

$2 \mathrm{OR}=$ Odd ratio; $\mathrm{CI}=$ confidence interval; $\mathrm{BMI}$ : body mass index

3 aWe transformed the continuous variables of maternal pre-delivery BMI into categorical

4 variables by the cutoff point 


\section{Figure 1 (on next page)}

Participants' selection after excluding neonatal and maternal factors from 1753 neonates. 
1753 singleton births in the hospital

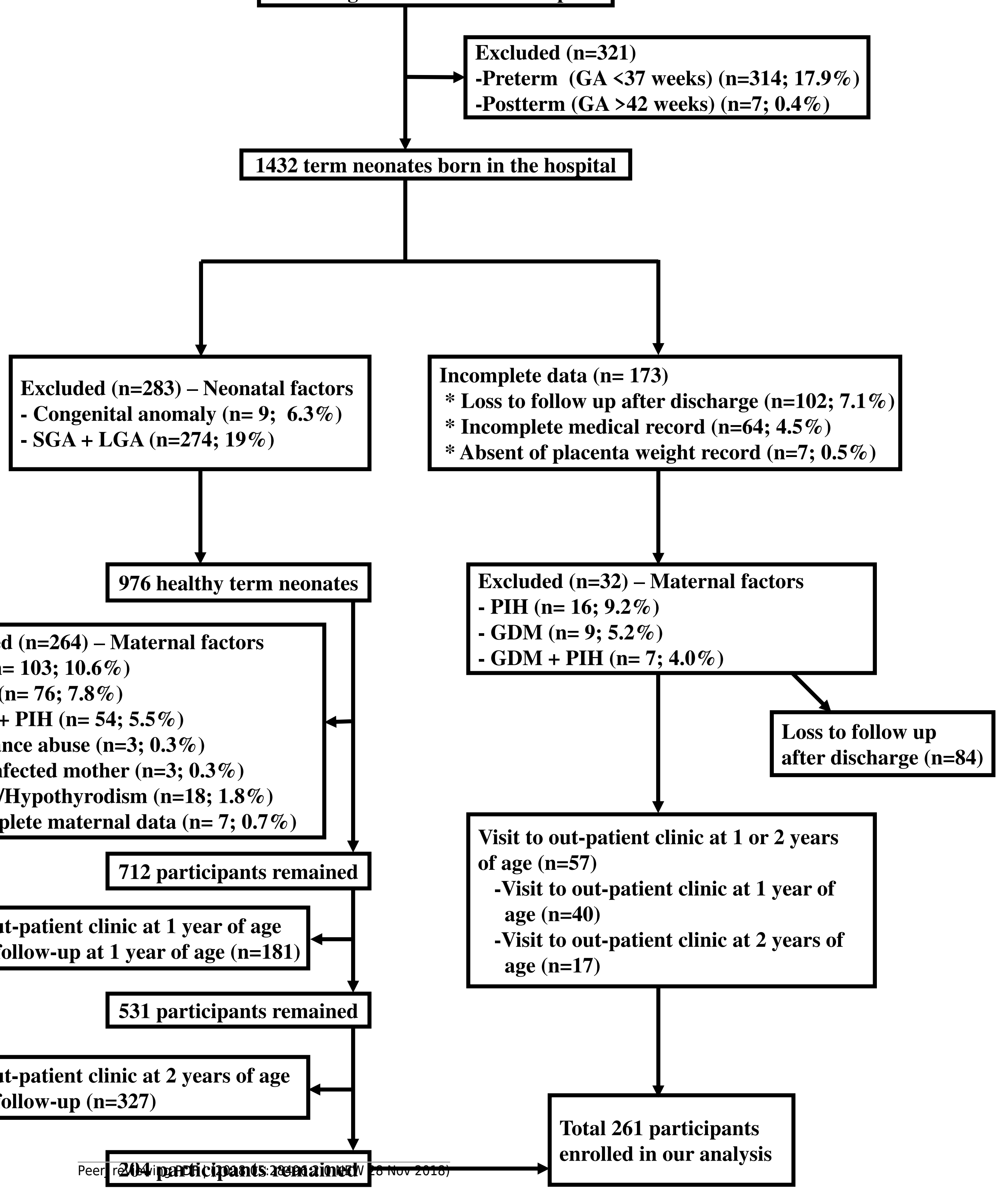


Figure 2 (on next page)

ROC curve of maternal pre-delivery body mass index for predicting offspring obesity at 2 years of age. 


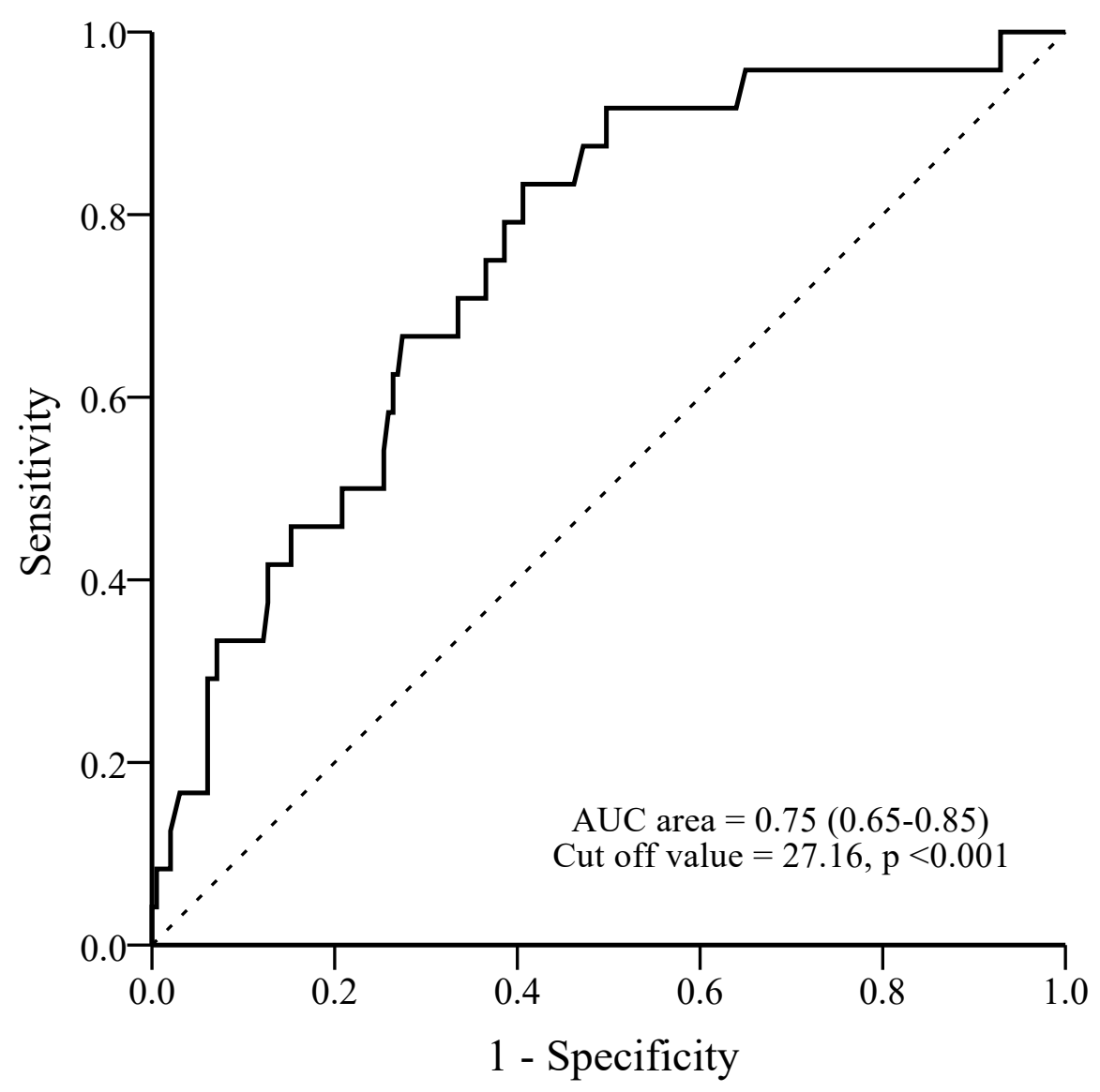

